Intersections

Canadian Journal of Music

Revue canadienne de musique

\title{
Addendum pour Intersections 27-1
}

Volume 27, numéro 1, 2006

URI : https://id.erudit.org/iderudit/1013160ar

DOI : https://doi.org/10.7202/1013160ar

Aller au sommaire du numéro

Éditeur(s)

Canadian University Music Society / Société de musique des universités canadiennes

ISSN

1911-0146 (imprimé)

1918-512X (numérique)

Découvrir la revue

Citer ce document

(2006). Addendum pour Intersections 27-1. Intersections, 27(1), i-16.

https://doi.org/10.7202/1013160ar

All Rights Reserved (C) Canadian University Music Society / Société de musique des universités canadiennes, 2007
Ce document est protégé par la loi sur le droit d'auteur. L'utilisation des services d'Érudit (y compris la reproduction) est assujettie à sa politique d'utilisation que vous pouvez consulter en ligne.

https://apropos.erudit.org/fr/usagers/politique-dutilisation/
Cet article est diffusé et préservé par Érudit.

Érudit est un consortium interuniversitaire sans but lucratif composé de l’Université de Montréal, l’Université Laval et l’Université du Québec à Montréal. Il a pour mission la promotion et la valorisation de la recherche. https://www.erudit.org/fr/ 
Dear Subscribers and Readers:

During the printing of Intersections volume 27, number 1, a technical problem arose with the quality of the reproduction in the majority of examples to the article by Russ Manitt, "Exploration morphologique et sémantique des leitmotive communs à Tristan und Isolde et aux Wesendonck-Lieder de Richard Wagner." To correct the situation, we have decided to insert in copies of the journal an Addendum, a new printing of all the musical examples to the article. We wish to express our profound regrets to the author and to our readers for the inconvenience this may cause. The source of the problem has been identified, and thus we are in a position to prevent its recurrence.

Chers abonné(e)s, lecteurs et lectrices,

Lors de l'impression du numéro $27 / 1$ d'Intersections, un problème technique a affecté Ta qualité de reproduction de la majorité des exemples musicaux de l'article de Russ Manitt, « Exploration morphologique et sémantique des leitmotive communs à Tristan und Isolde et aux Wesendonck-Lieder de Richard Wagner ». Pour corriger la situation, nous avons décidé d'insérer dans les copies de la revue un Addendum offrant une nouvelle impression de bonne qualité de l'ensemble des exemples musicaux de cet article. Nous exprimons nos plus vifs regrets à l'auteur et à tous nos lecteurs et lectrices pour les désagréments que cela pourrait leur causer, et nous tenons à les assurer que la source du problème a été identifiée, et que nous sommes donc en mesure de prévenir à l'avenir la répétition d'incidents de même nature.

The editors/Les éditeurs

François de Médicis

Murray Dineen. 
ADDENDUM POUR INTERSECTIONS 27-1

EXPLORATION MORPHOLOGIQUE ET SÉMANTIQUE DES

LEITMOTIVE COMMUNS À TRISTAN UND ISOLDE ET AUX

WESENDONCK-LIEDER DE RICHARD WAGNER

\section{Russ Manitt}

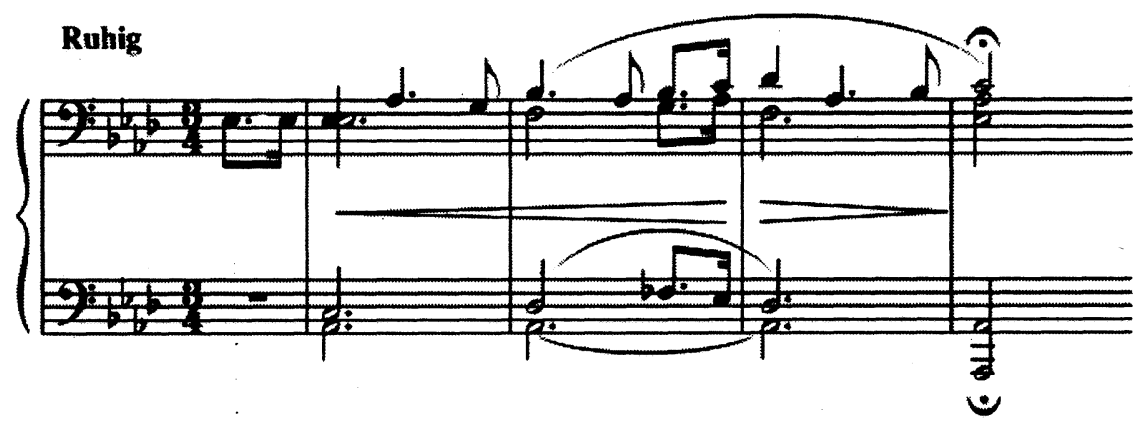

Exemple 1a

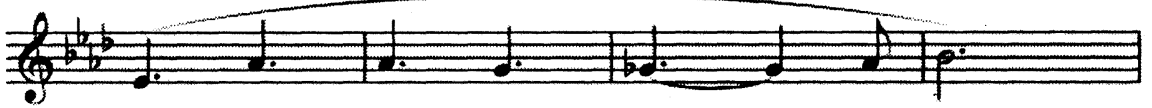

Exemple 1b

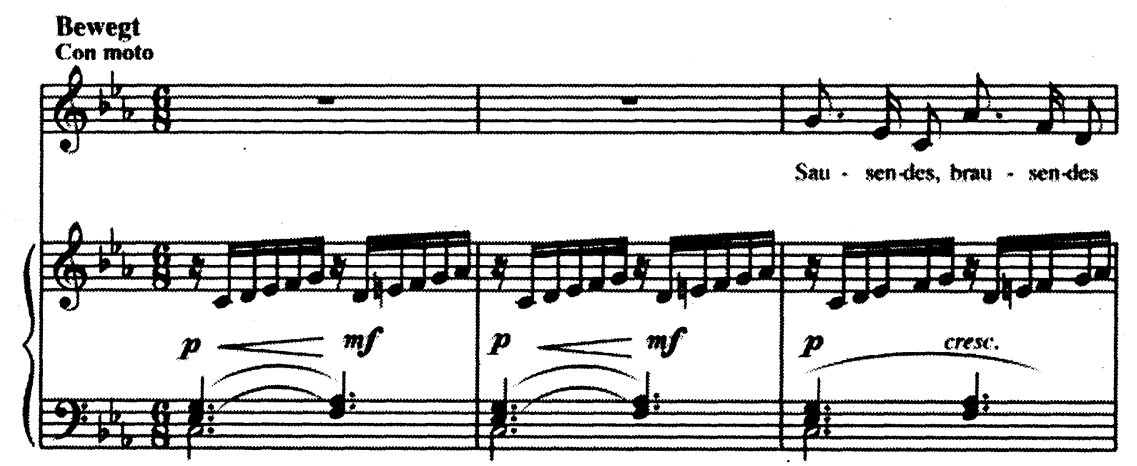

Exemple 2a 


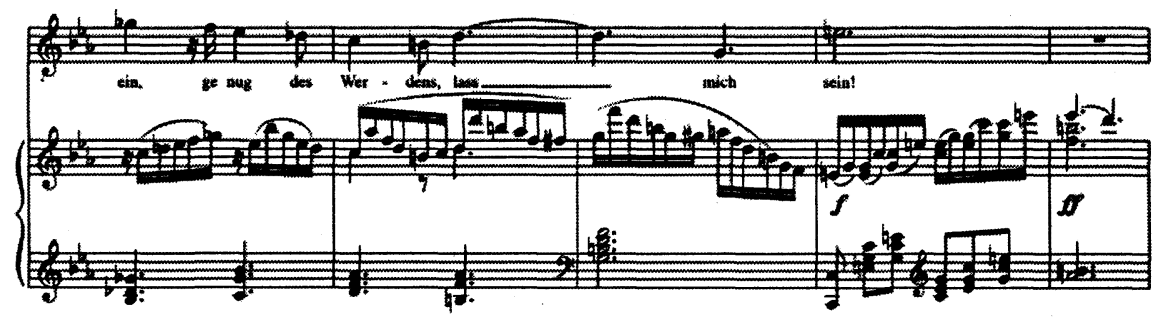

Exemple 2b

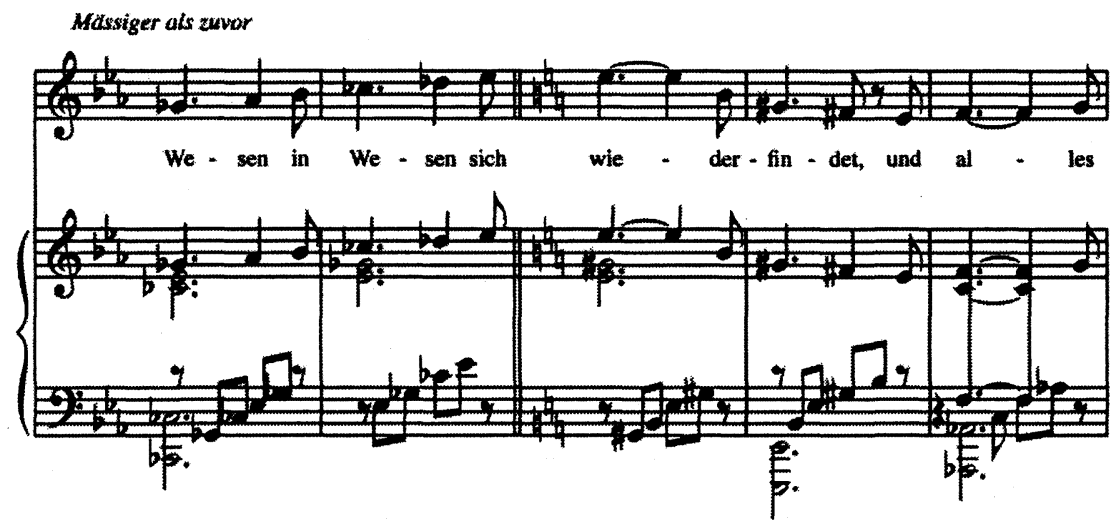

Exemple 2c

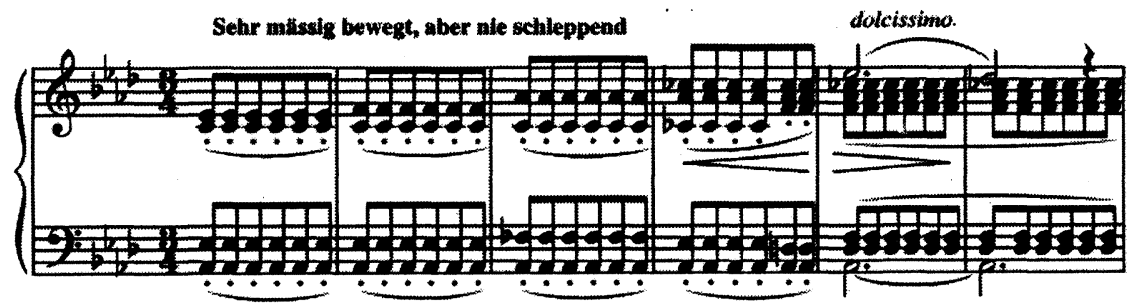

Exemple 3a 


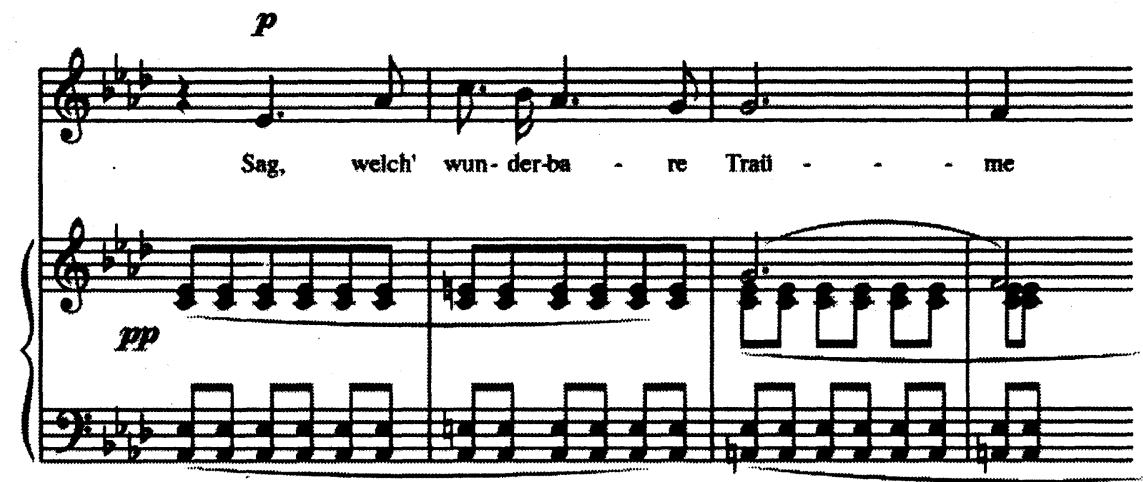

Exemple $3 \mathrm{~b}$

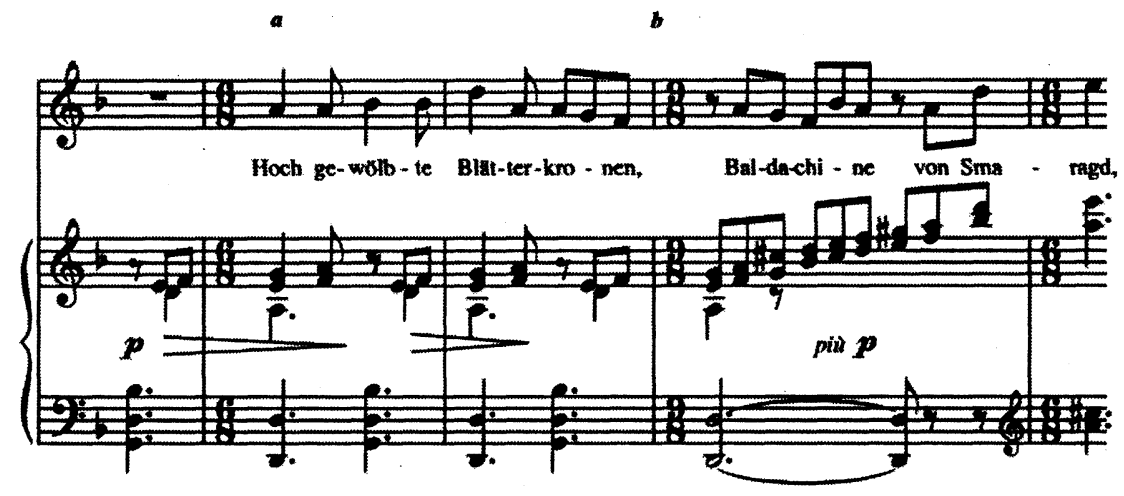

Exemple 3c

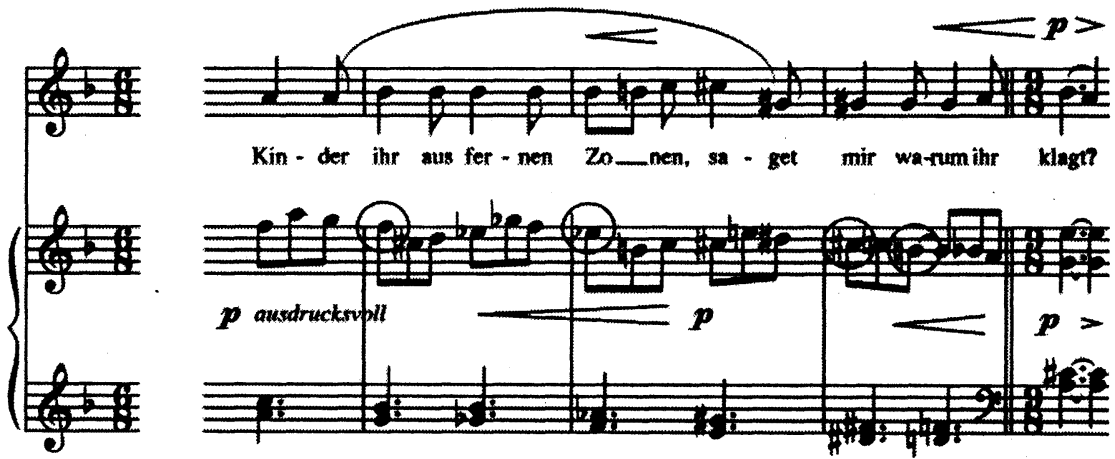

Exemple 3d 

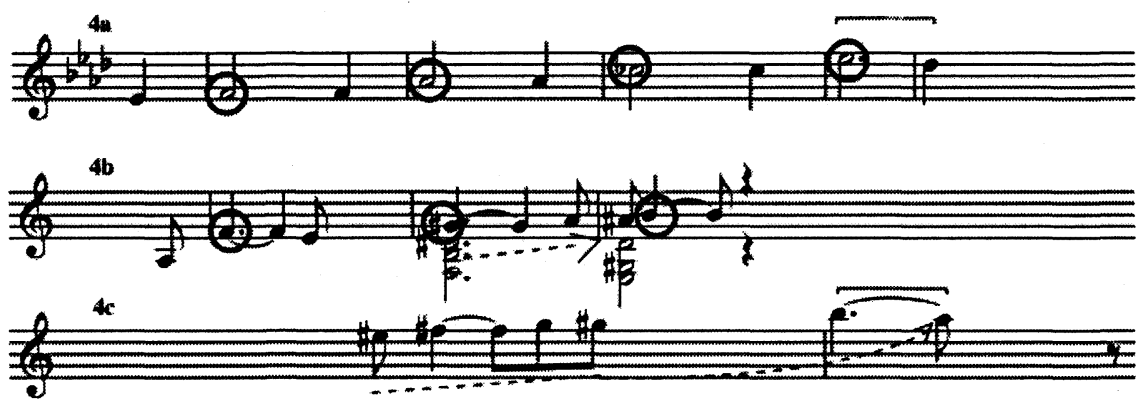

Exemple 4 

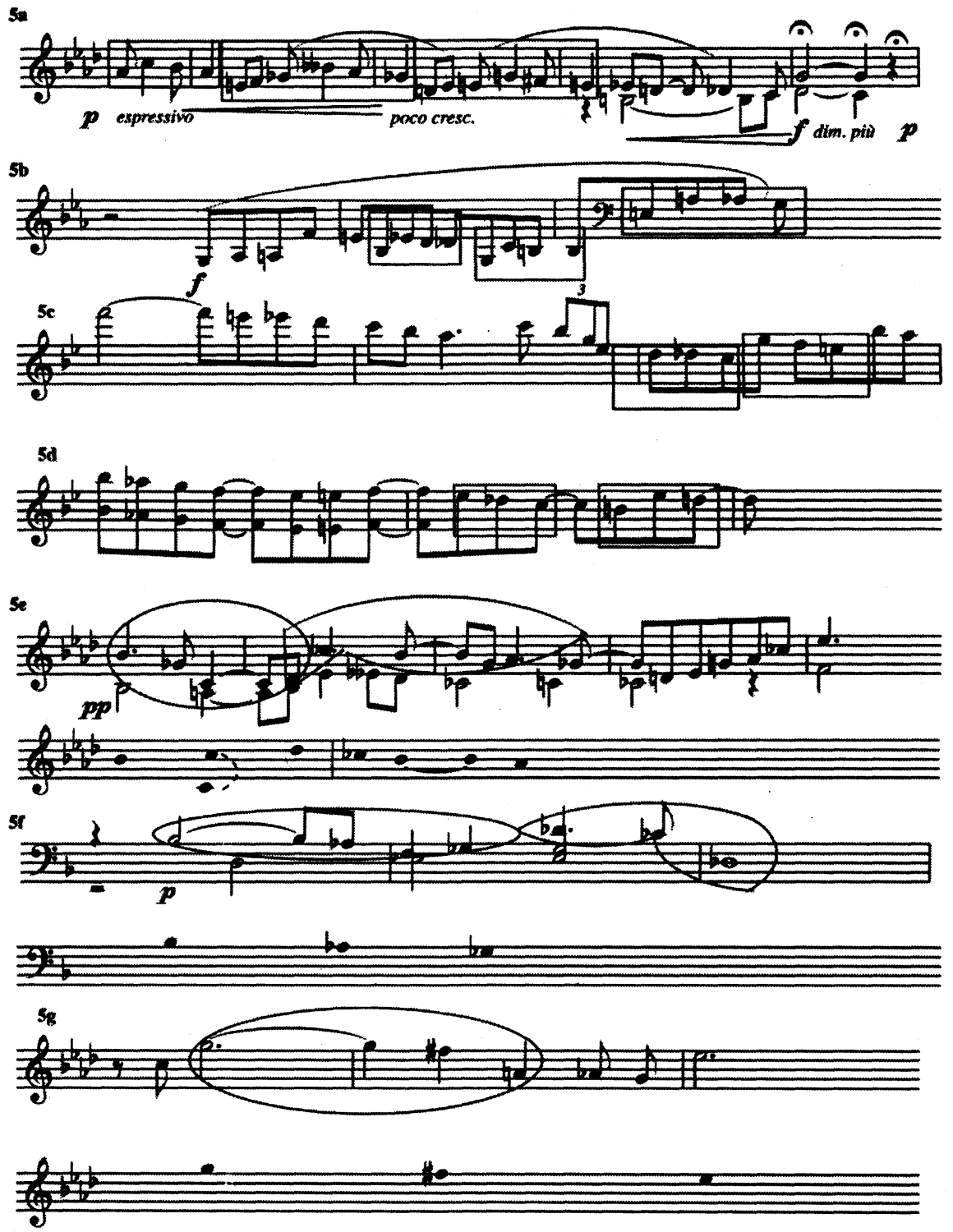

Exemple 5 
?

6b

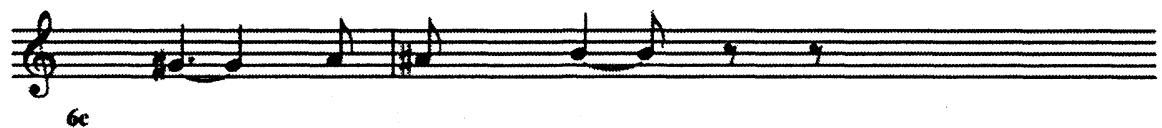

6

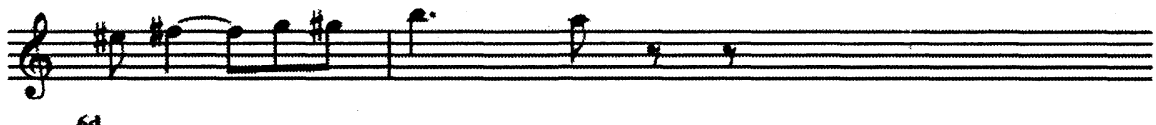

6d

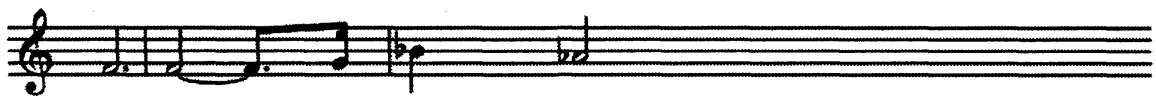

6

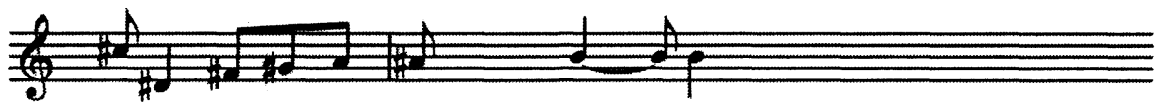

Exemple 6

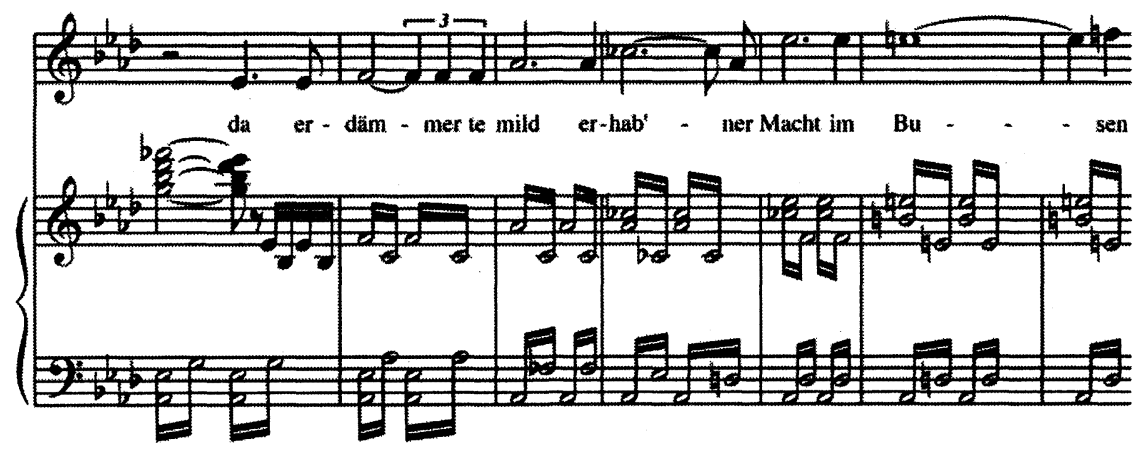

Exemple 7a 


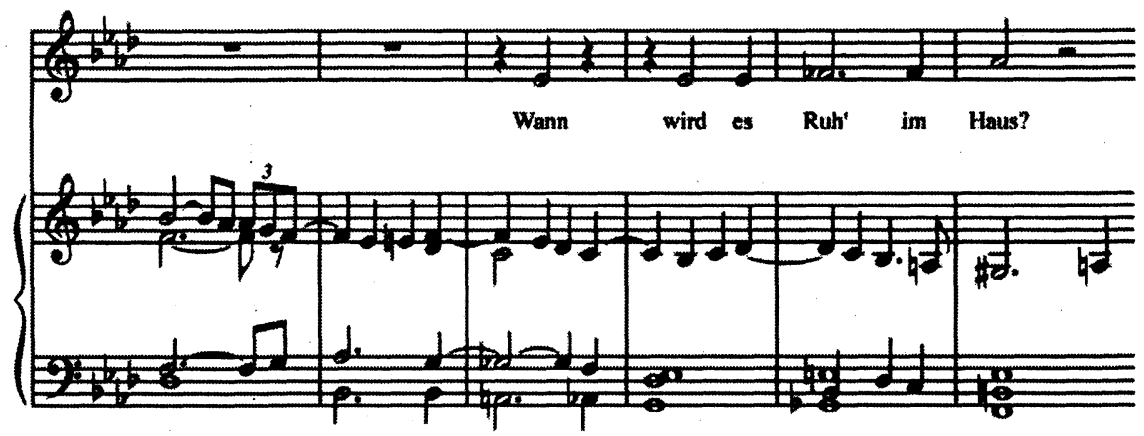

Exemple 7b

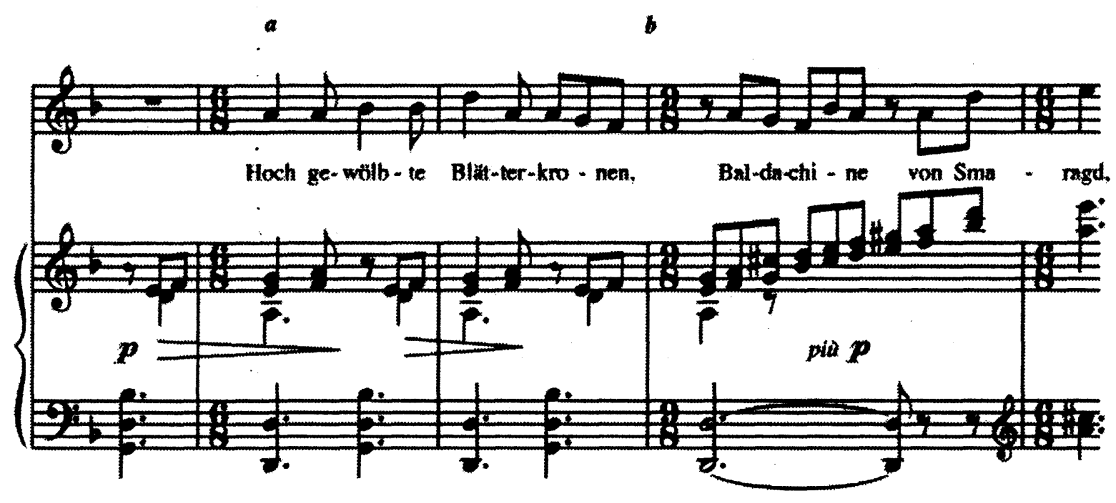

Exemple 8a

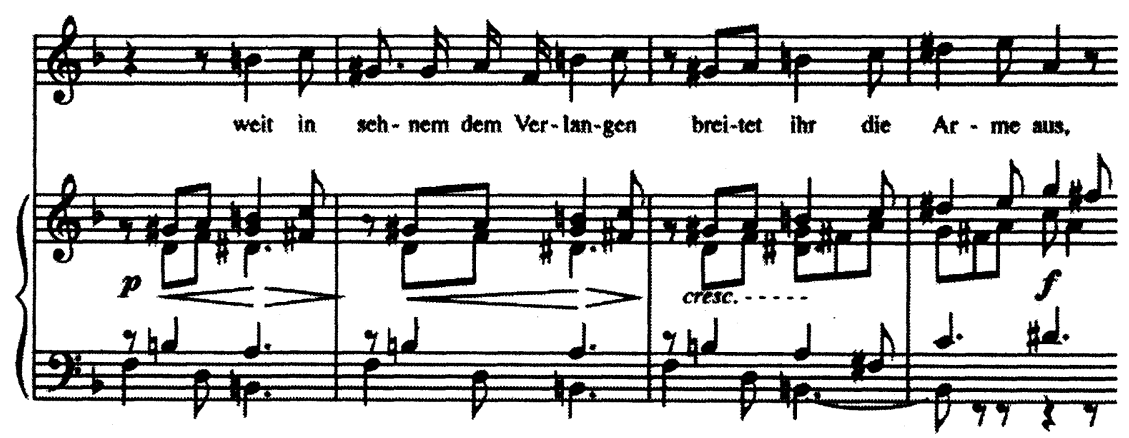

Exemple 8b 


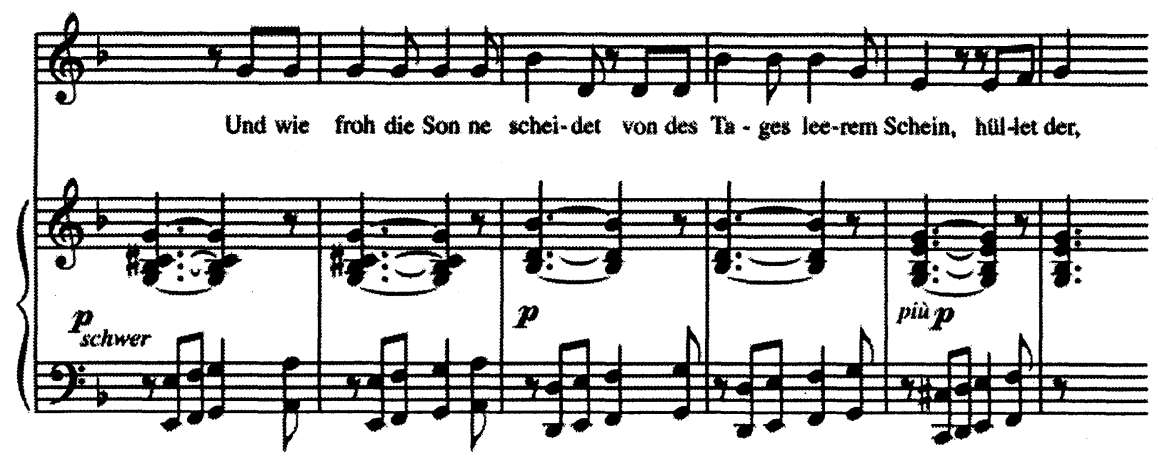

Exemple 8c

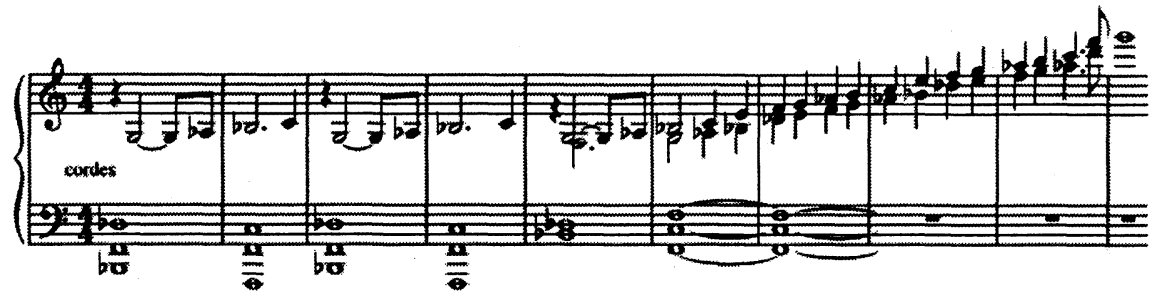

Exemple 8d
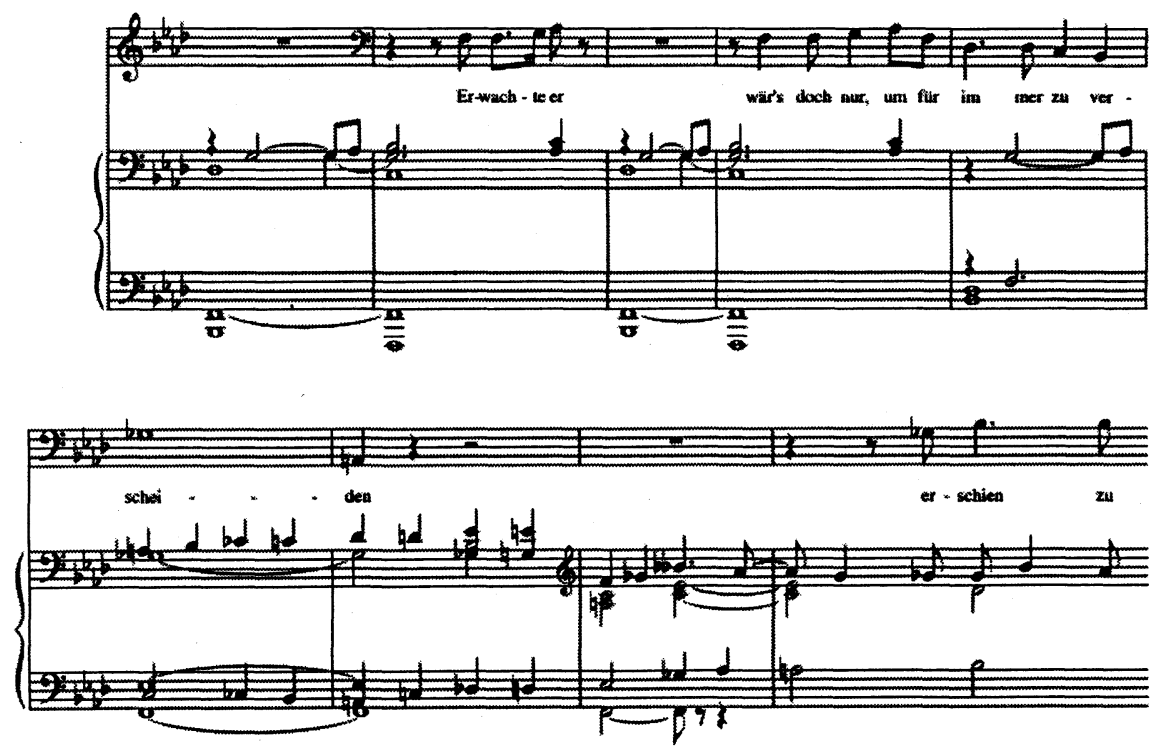

Exemple 8e 


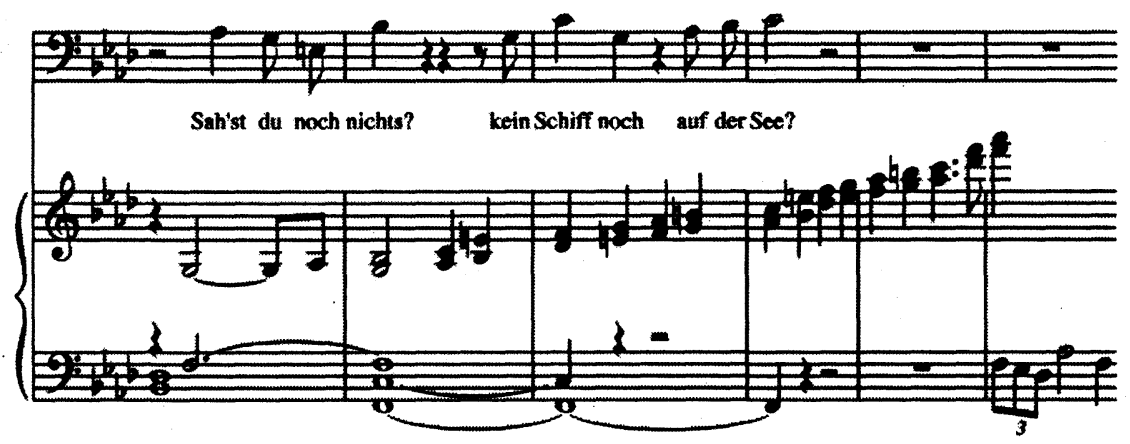

Exemple 8f
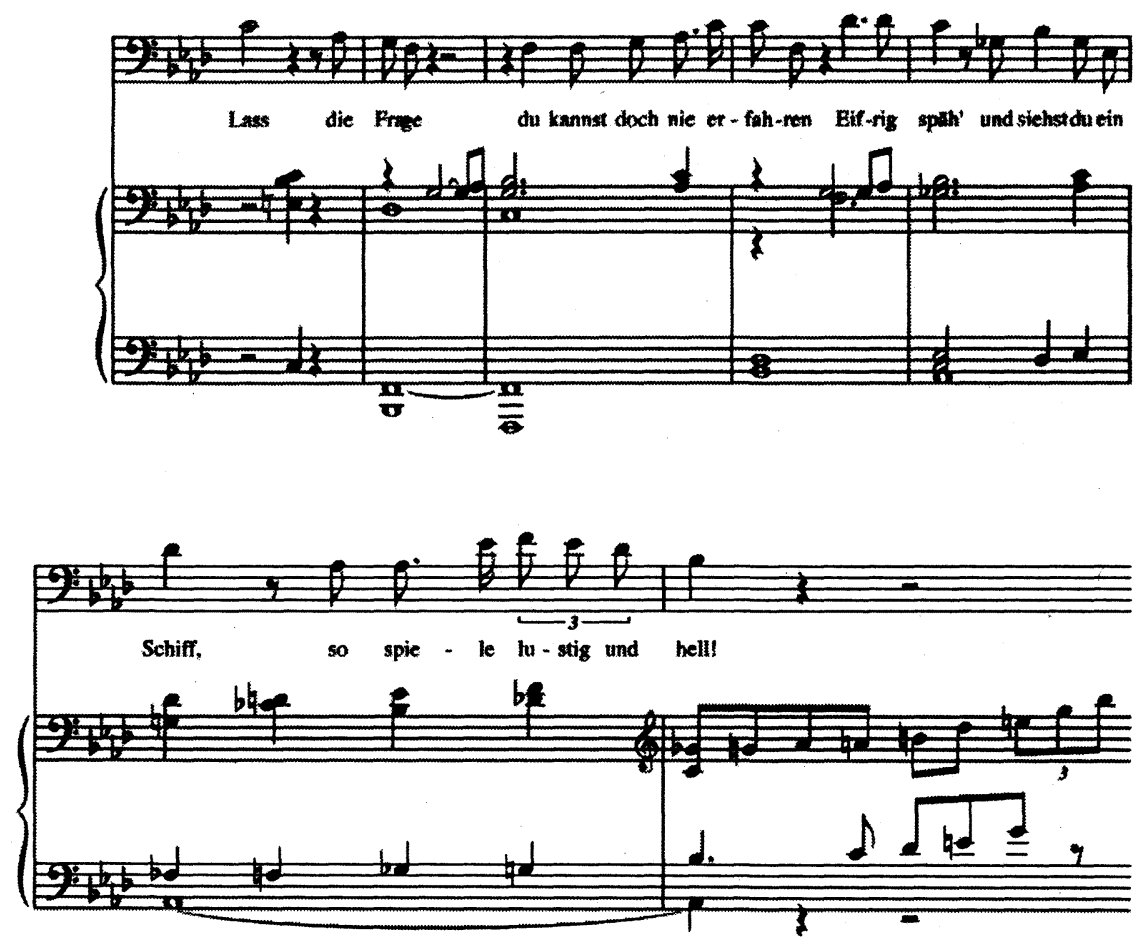

Exemple 8g 


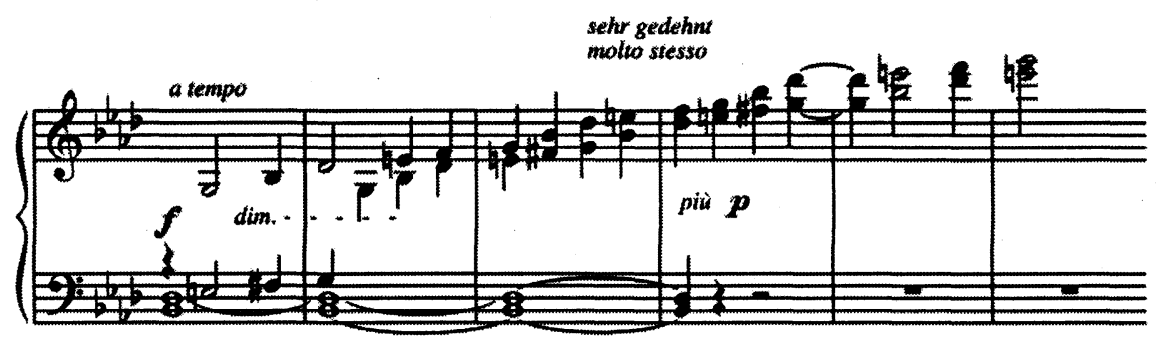

Exemple 8h

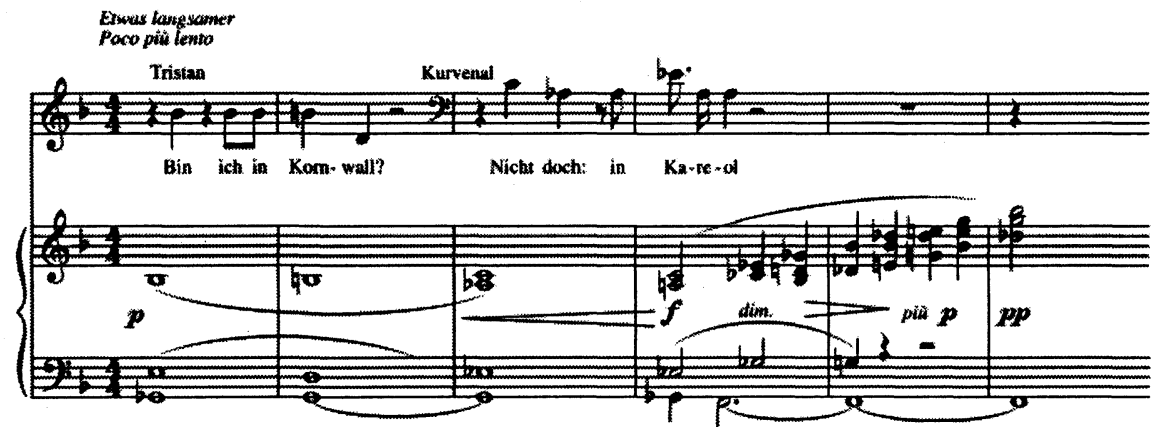

Exemple 8i 

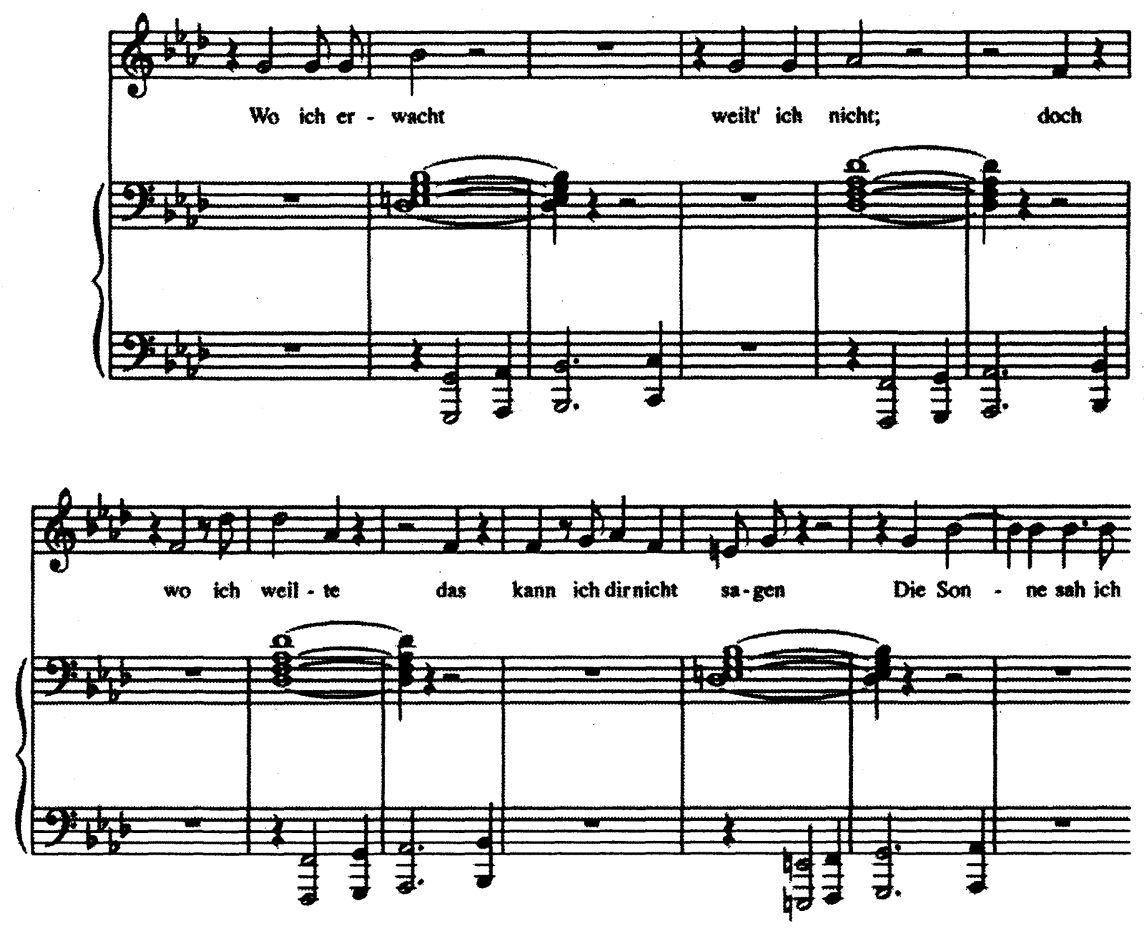

Exemple 8j

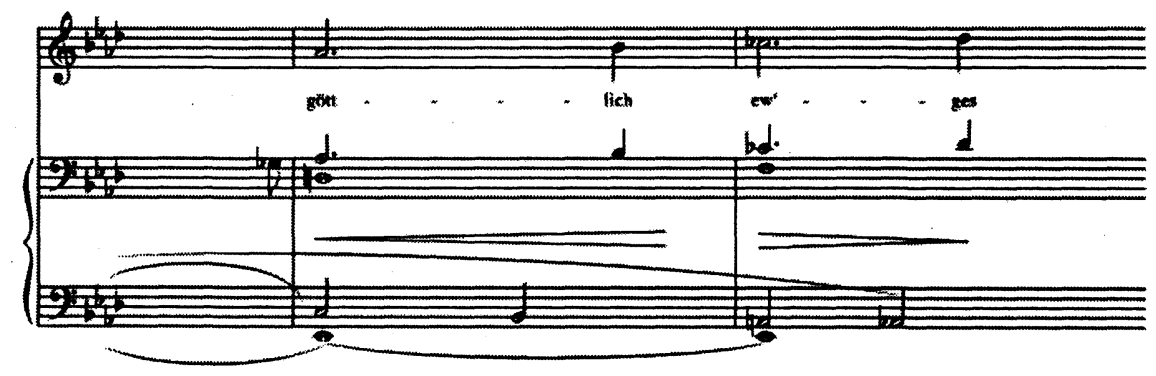

Exemple 8k 


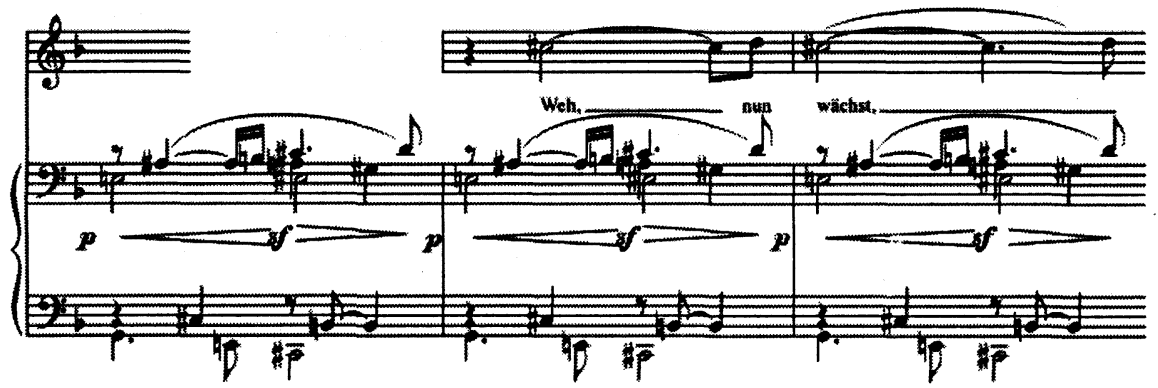

Exemple 81
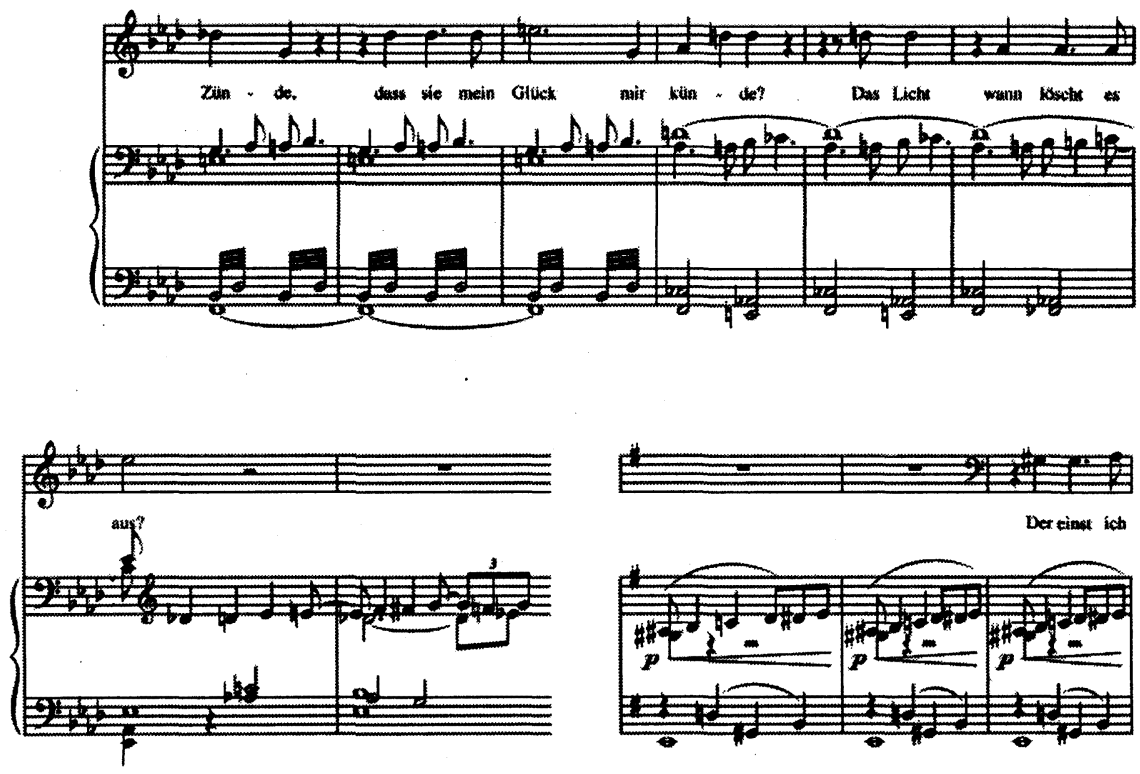

Der einat ich
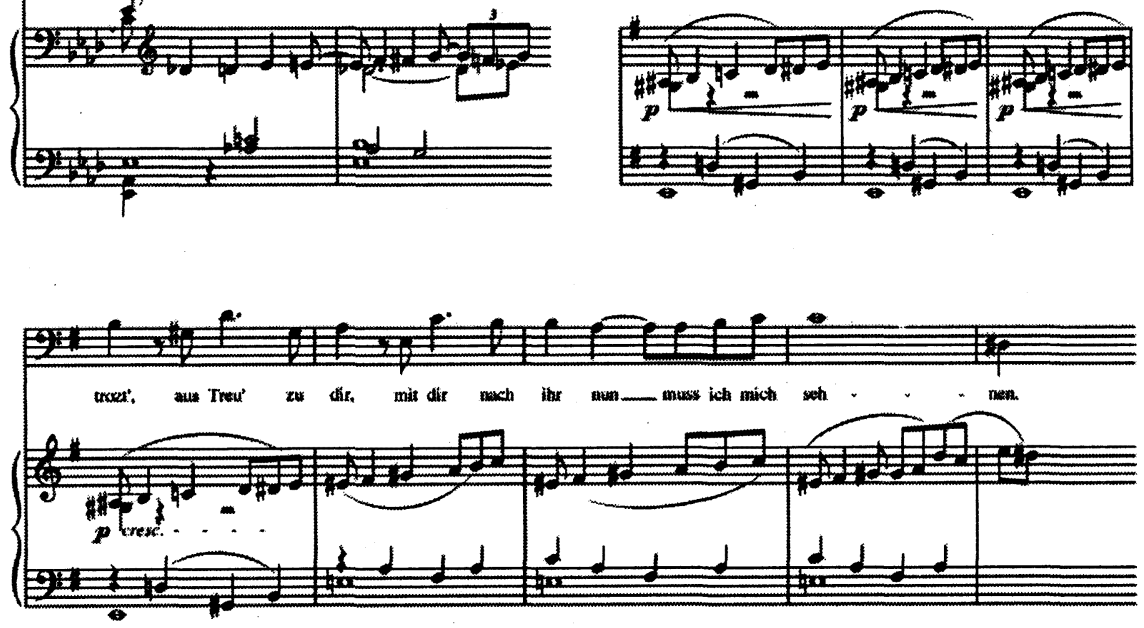

Exemple 8m 


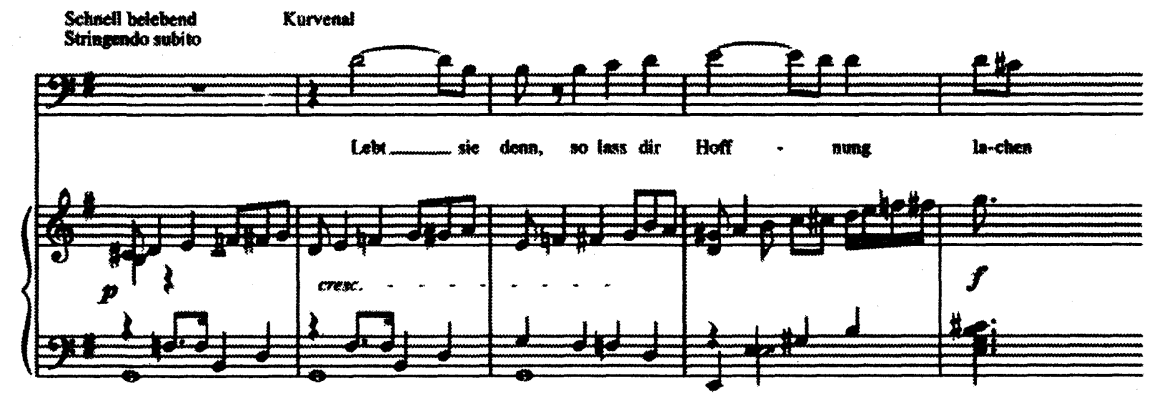

Exemple 8n
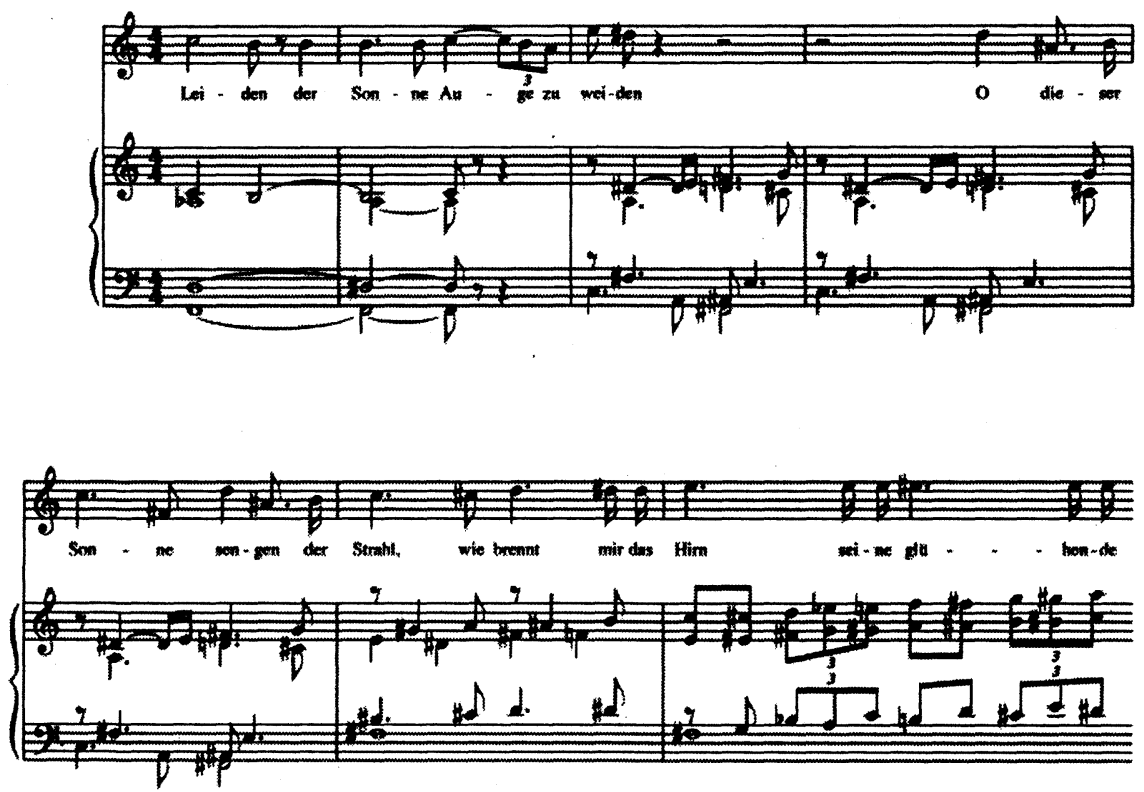

Exemple 80 


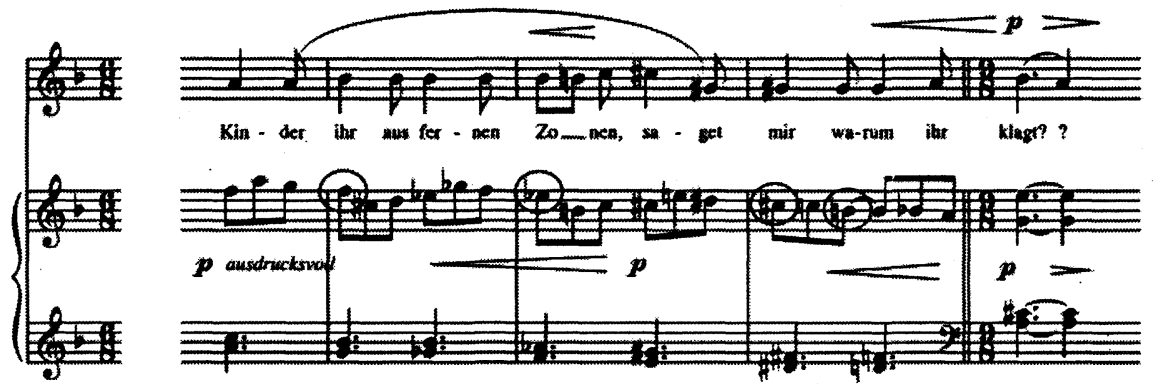

Exemple 9a

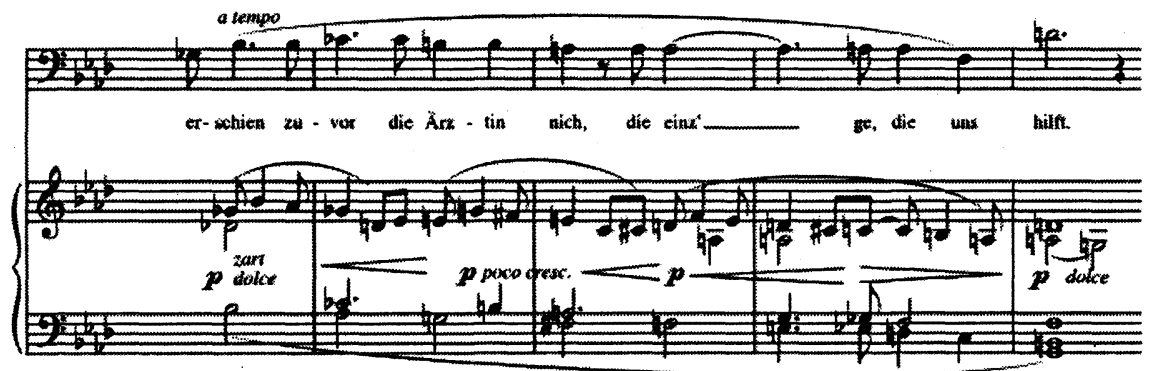

Exemple 9b 

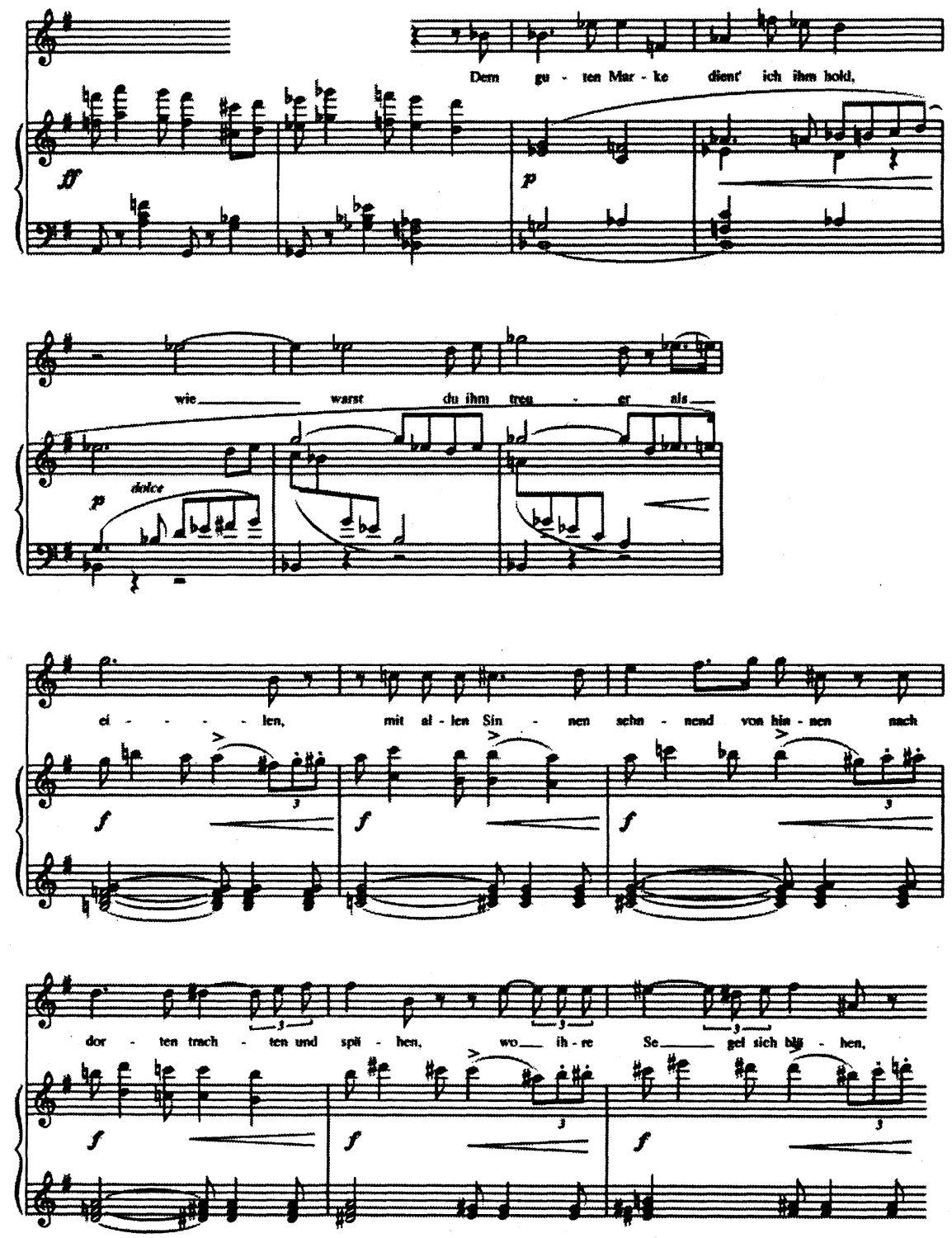

Exemple 9c 

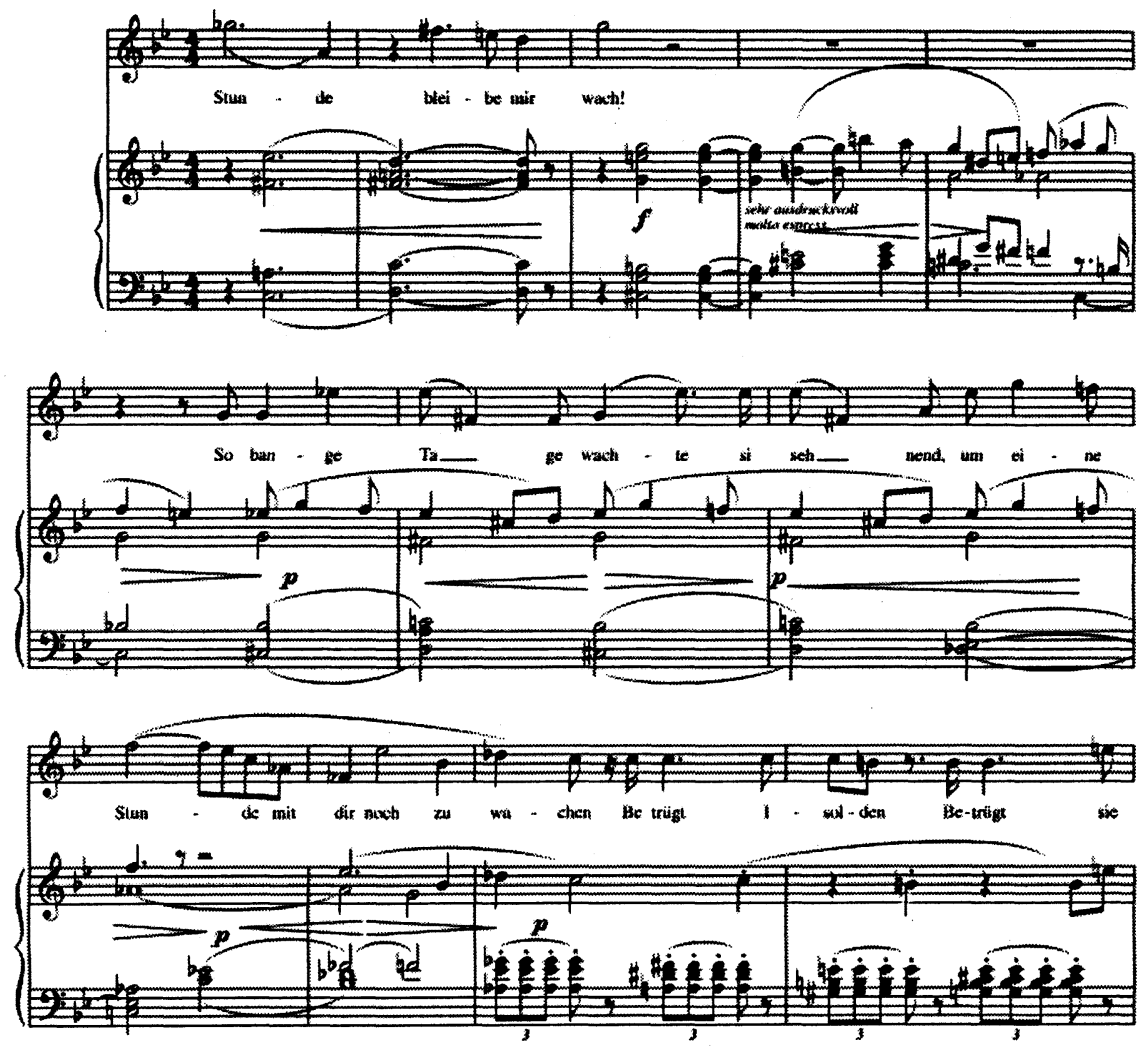

Exemple 9d 